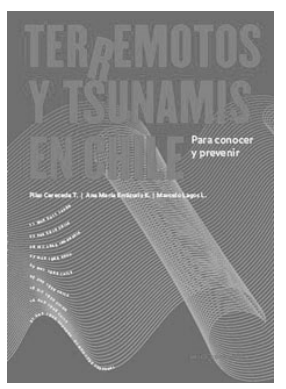

\title{
Pilar Cereceda T., Ana María Errázuriz K. y Marcelo Lagos. Terremotos y tsunamis en Chile: para conocer y prevenir.
}

\author{
Santiago de Chile: Origo Ediciones, 2011. 128 p.
}

\author{
Loreto Tamburini González
}

Chile se localiza en una de las áreas sísmicas más activas de la Tierra. En promedio, en los últimos cinco siglos, un terremoto destructor de magnitud superior a 8 se ha producido cada 10 años en alguna parte del territorio chileno (Barrientos et al., 2004). El más reciente se produjo el 27 de febrero de 2010, seguido de un tsunami que causó gran devastación a lo largo de la costa del centro de Chile, impactando severamente el territorio comprendido entre Pichilemu $\left(34.39^{\circ} \mathrm{S}\right)$ y Puerto Saavedra $\left(38.81^{\circ} \mathrm{S}\right)$ (Horton et al., 2011). Además, el tsunami afectó las islas del archipiélago de Juan Fernández y se extendió por todo el océano Pacífico (Arriagada et al., 2011). La pérdida económica causada por el terremoto y el tsunami en su conjunto, se ha estimado en 30 mil millones de dólares, con aproximadamente 200.000 casas dañadas y una pérdida de vidas humanas del orden de 521 víctimas (Xue et al., 2010).

Conscientes de la necesidad de aportar en el conocimiento respecto a estos fenómenos, sobre todo después de este trágico acontecimiento, Pilar Cereceda, Ana María Errázuriz y Marcelo Lagos, destacados académicos del Instituto de Geografía de la Pontificia Universidad Católica de Chile, han elaborado un libro que tiene como principal objetivo educar a la población para la prevención de desastres y la mitigación de sus efectos. Como bien expresan los autores: "Con el

\footnotetext{
1 Laboratorio de Investigación de tsunamis UC, Instituto de Geografía, Pontificia Universidad Católica de Chile (Chile). E-mail: Itamburi@uc.cl
}

firme propósito de contribuir a la educación de niños, jóvenes y adultos para prevenir los desastres que puedan producirse con los terremotos y tsunamis, es que entregamos esta obra. Para que cada persona se prepare adecuadamente, es necesario poner a su disposición el conocimiento científico de estos fenómenos naturales".

El libro se estructura en cuatro grandes temas: en el primero de ellos, denominado "La Tierra, un planeta inquieto", se expone de forma gráfica y explicativa, la estructura interna de la Tierra y sus características físicas, con énfasis en las placas tectónicas y fondos oceánicos como lugares generadores de terremotos y tsunamis.

Posteriormente, le sigue "Por qué se mueve la Tierra", en el que se examinan en detaIle las ondas sísmicas, las escalas de magnitud e intensidad, la posible predicción de los terremotos y los eventos ocurridos en el país desde el siglo XVI.

En "Más allá de una ola gigante", se enseña la física, comportamiento y orígenes de las ondas de tsunami, destacando la actividad sísmica como su principal causa, tomando como ejemplo los efectos devastadores producidos por el terremoto del 27 de febrero de 2010 en el centro de Chile, para concluir el capítulo relatando la historia de grandes tsunamis en Chile.

Finalmente, en "Una tarea de todos", se insiste en la prevención de desastres como una tarea tanto de los organismos especializados como de las personas en particular, 
altamente relacionada con la educación y concientización, que permita reducir la vulnerabilidad y fortalecer las capacidades de hacer frente a los desastres naturales. Con el objetivo de aumentar el conocimiento de los lectores de esta obra, se definen una serie de conceptos fundamentales en materias de reducción de riesgos de desastres, se describe la institucionalidad nacional como internacional encargada de prevenir, monitorear y proteger a la sociedad civil frente a estas amenazas, para finalizar con una serie de recomendaciones a seguir.

Si bien el libro está orientado al público en general, esto no significa que no sea un excelente material para ser consultado por estudiantes, profesionales y académicos relacionados con las materias tratadas. Asimismo, las aplicaciones de este libro van desde lo meramente educativo, que se potencia con una gran cantidad de imágenes ilustrativas de los fenómenos en cuestión, y un lenguaje claro y sencillo, que mezcla el rigor científico de los temas tratados con un enfoque pedagógico, hasta su uso como una guía práctica que puede ser consultada por las familias para conocer y prevenir los riesgos de terremotos y tsunamis.

Así, Terremotos y tsunamis en Chile es un gran aporte a la comprensión de estos fenómenos, que viene a llenar un vacío en la bibliografía existente sobre estos temas en el país. Se espera que sea un material de consulta disponible en bibliotecas y establecimientos educacionales y se transforme en el primero de muchos libros orientados a la educación de otros fenómenos naturales extremos que afectan al territorio nacional.

\section{Referencias bibliográficas}

ARRIAGADA, C.; ARANCIBIA, G.; CEMBRANO, J.; MARTÍNEZ, F.; CARRIZO, D.; VAN SINT JAN, M.; SÁEZ, E.; GONZÁLEZ, G.; REBOLLEDO, S.; SEPÚlVEDA, S.A.; CONTRERAS-REYES, E.; JENSEN, E. \& YÁ$\tilde{N} E Z, G$. Nature and tectonic significance of co-seismic structures associated with the Mw 8.8 Maule earthquake, central-southern Chile forearc. Journal of Structural Geology, 2011, $N^{\circ} 33$, p. 891-897.

BARRIENTOS, S.; VERA, E.; ALVARADO, P. \& MONFRET, T. Crustal seismicity in central Chile. Journal of South American Earth Sciences, 2004, N²16, p. 759-768.

HORTON, B.; SAWAI, Y.; HAWKES, A. \& WITTER, R. Sedimentology and paleontology of a tsunami deposit accompanying the great Chilean earthquake of February 2010. Marine Micropaleontology, 2011, N 79, p. 132-138.

XUE, Y.; LIU, J. \& LI, G. Characteristics of seismic activity before Chile MW8.8 earthquake in 2010. Earthquake Science, 2010, N ${ }^{\circ}$ 23, p. 333-341 